\title{
HOW DO I USE MUSIC THERAPY TO SUPPORT THE INTERPERSONAL COMMUNICATION OF CHILDREN WITH LEARNING SUPPORT NEEDS AT A MAINSTREAM PRIMARY SCHOOL?
}

\author{
Anna Sedcole
}

An exegesis submitted to Victoria University of Wellington in partial fulfilment of the requirements for the degree of

Master of Music Therapy

Te Kōkī - New Zealand School of Music 


\section{ABSTRACT}

This research focuses on one student's experience of using music therapy to support the interpersonal communication skills of children in a mainstream primary school. Using firstperson research as a methodological approach (Hunt, 2016), I examined the rich, qualitative data I had collected in my clinical notes as part of my practice. I used secondary analysis of data using thematic analysis to code, categorise, and detect themes in the data, which then enabled me to tell my story. I drew on music therapy literature which described the communication challenges children with learning support needs typically experience (for example, those with autism spectrum disorder and attention deficit hyperactivity disorder), as well as literature on interpersonal skills such as turn-taking and joint attention. Although early research shows that music therapy interventions can support interpersonal communication skills, the research on children with various learning support needs in New Zealand is still scant. My research will add to this literature by describing some of the ways music therapy is used with three children who have various learning support needs in a mainstream school environment in New Zealand. 


\section{ACKNOWLEDGEMENTS}

I would like to acknowledge and thank the following people:

My supervisor, Associate Professor Daphne Rickson, for her unwavering support, feedback, and helpful timely advice, for which I am extremely grateful;

Associate Professor Sarah Hoskyns, Penny Warren, and Megan Berentson-Glass, for their wisdom, guidance and advice during this degree;

My fellow students, for their support, encouragement and

friendship during these past few years;

My parents, Richard and Marion,

for paying for years of music lessons, and for proofreading this exegesis;

My children, Alexander and Zoe,

who put up with their mother studying in the evenings and weekends;

and finally - to my husband Michael, for believing in me. 


\section{TABLE OF CONTENTS}

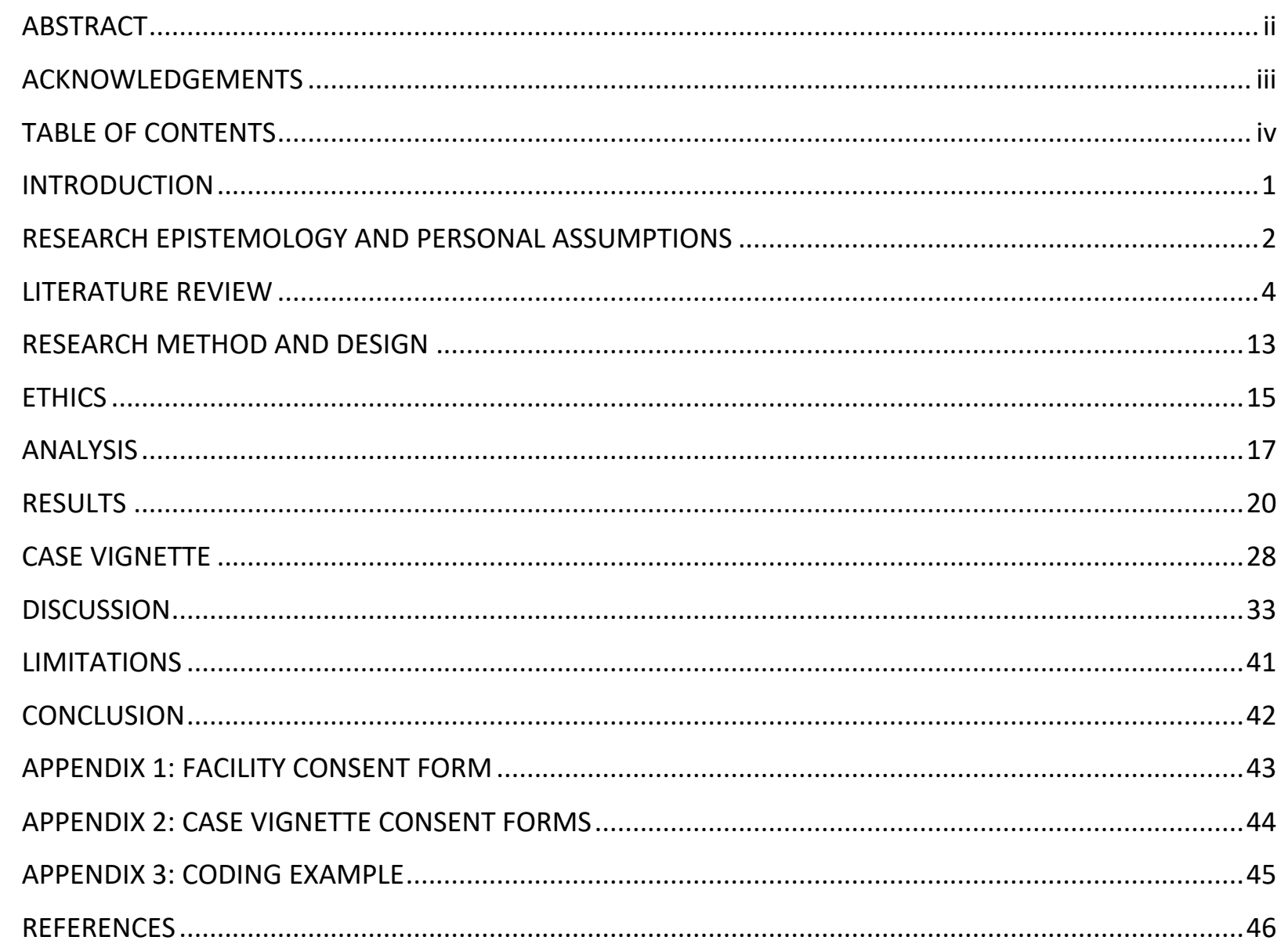




\section{INTRODUCTION}

Communication is a very broad term, encompassing all aspects of human interaction, including spoken language, gestures, and sign language, as well as musical interactions. As social animals, human beings have complex language, and respond to non-verbal social cues that enable us to work and interact with other people. Social communication sets us apart from other animals, but it is often difficult for children who have learning support needs, such as autism spectrum disorder (ASD), attention deficit hyperactivity disorder (ADHD), or other social and behavioural challenges, to communicate effectively. Current research suggests that music therapy may be effective at promoting interpersonal communication for children with learning support needs, but further research needs to be done in this area (Carpente, 2017; Geretsegger et al., 2014; Kim, Wigram \& Gold, 2009; LaGasse, 2014; Porter et al., 2012; Rickson, 2019; Spiro \& Himberg, 2016; Thompson, McFerran \& Gold, 2014; Thompson \& Skewes McFerran, 2015; Vaiouli, Grimmet \& Ruich, 2013).

As part of my Master of Music Therapy degree requirements, I completed a placement at a full primary school which had several students with high needs as well as many other students with various learning support needs on its roll. I was therefore interested in how I used music therapy to support the interpersonal communication of these children. The focus of music therapy sessions with these children depended on their existing abilities and identified goals, including their ability to listen, to sustain joint attention (attending to an object with someone else), to imitate, and to take turns. As a sole researcher on placement at the school, I looked at my own practice to identify how I supported the children's communication. Thus, my research question was:

How do I use music therapy to support the interpersonal communication of children with learning support needs at a mainstream full primary school? 


\section{RESEARCH EPISTEMOLOGY AND PERSONAL ASSUMPTIONS}

Deciding upon a research topic and subsequent methodology requires a lot of careful and reflexive thought. McFerran and Silverman (2018) suggest that students considering a potential research topic ask themselves to think about what drew them to music therapy in the first place. They also recommend thinking about how ontology - or what we believe is real shapes the research question, so they encourage students to ask themselves why they believe music will help with the particular population chosen.

Upon reflection, I realised that I was really interested in the power of communication within music therapy. My own personal experience of being led towards music therapy was that of my grandmother's final days. Lying in her hospital bed at the rest home she lived in, she was drifting in and out of consciousness. When I came to visit her, my mother warned me that she was mostly unresponsive. I had thought to bring some music with me, thinking it might be nice to sing something at her bedside, since she was not responding much to talking. I began to hum a tune by Tchaikovsky (Hymn of the Cherubim), and she immediately turned to me. My grandmother was not particularly drawn to music, and we hadn't connected especially over it, so I was surprised it had such an effect (although I did discover after she died that she played the piano as a child). My mother told me that after I visited her, she was quite lucid and was able to talk to people. I realised that music could be a powerful communication tool when speech and other non-verbal communication skills were not able to be used, and I subsequently started thinking about studying music therapy. I therefore decided that communication should be a central part of my enquiry in this research project.

Qualitative research is necessarily personal, argues Bruscia (2005), with the values and beliefs of the researcher being integral to the process. Indeed, qualitative research can be deeply human, with the overall goal being to discover meaning (Wheeler \& Kenny, 2005). When adopting a constructivist or interpretivist philosophical stance, qualitative researchers assume that there are multiple realities, rather than one truth to be uncovered; that the 
researcher's background influences the findings; and that data is constructed and the analysis is subjective rather than objective (Matney, 2019; O'Callaghan, 2012; Wheeler, 2005). Researchers who use qualitative methodology often aim to provide rich descriptions of humans' social experiences, genuinely attempting to understand something about being human by using approaches that take advantage of being human (Bruscia, 1995; Tate \& Happ, 2018).

Music is conceptual and emotional, and experiences with it are often difficult to quantify. Because I was interested in construing meaning from the communications within these music therapy sessions, and I believed that I was not discovering a single, objective truth but I was assuming that there was more than one reality, then my work could fall into a constructivist or interpretivist paradigm. Constructivists also believe that the researcher and the subject interact to influence each other, and that time- and context-free generalisations are not possible (Wheeler \& Kenny, 2005). Thus, the methodology I adopted involved collecting qualitative data, which was then analysed and developed into themes.

In this study I used first-person research methodology (Hunt, 2016) and adopted secondary analysis of data (Bishop, 2011) using thematic analysis. First-person research involves researchers or participants studying themselves (Hunt, 2016). Because I was uncovering my own 'practice wisdom' through a reflexive review of my own clinical records (O'Callaghan et al., 2009), then the research methodology aligns with first-person research. However, one aspect of my study which distinguishes it from many forms of first-person research is that it involved the retrospective analysis of data that was collected for another purpose. The data used for this study was not gathered or collected for the research - it already existed as practice data. Thus the methodology strongly aligns with a secondary analysis of data as outlined by Bishop (2011). 


\section{LITERATURE REVIEW}

\section{Background: Introducing the literature}

There is now a substantial body of literature involving music therapy and children with learning support needs, encompassing children with autism spectrum disorder (ASD), attention deficit hyperactivity disorder (ADHD), and other developmental delays, as well as other social and behavioural challenges, including trauma. The largest body of research on music therapy with children with communication challenges focuses on autism, and the efficacy of music therapy interventions with this population is now considered promising. Although this research is not focusing solely on children with ASD, it is useful to read many of these studies as interpersonal communication skills are often targeted. Music therapy literature that involves other diagnosed disorders, including ADHD and other developmental delays, are also outlined, as well as literature on children with behavioural and social issues.

\section{Defining interpersonal communication}

Communication is a broad term that encompasses all aspects of human interaction, although definitions may vary. At its core, communication consists of the transfer of a message between a sender and a receiver (Kho, 2011). As social animals, communication between human beings is essential for organising and ordering our lives, as well as making meaning and expressing feelings. This social communication includes verbal language, gesture, body language, and pre-verbal communication, such as the babble that babies use to 'talk' to their caregivers (Wigram, 1999).

Interpersonal communication, which could be considered a part of social communication, includes skills such as turn-taking (Schertz \& Odom, 2007) and joint attention, both in response and initiation (Mundy \& Stella, 2000, as cited in Thompson, 2012). Joint attention, the visual coordination of attention with someone else to an object or other external focus (Schertz \& Odom, 2007) is an important skill to develop because a person can then share 
experiences with others (Vaiouli, Grimmet \& Ruich, 2013). Children generally develop interpersonal skills from socialisation with their family members, particularly their primary caregivers. A baby develops an attachment with its caregivers during care-giving interactions (Pasiali, 2012), for example, as parents talk to an infant while changing their nappy. Such dyadic relationships are vitally important in a child's development and form the basis for subsequent human relationships and interpersonal communications (Malloch \& Trevarthen, 2009).

Terms in academic literature are often changing, and this can make researching a particular topic challenging. In New Zealand, 'learning support needs' is the current acceptable term for children who need extra support with their learning (Ministry of Education, n.d.), but for a long time they were referred to as children with special education needs. The field is sometimes still referred to as 'special education', even though the drive towards 'inclusive education' has been underway for several decades. Even the definition of interpersonal skills is not straightforward: many researchers refer to 'social skills', 'social reciprocity', or 'social communication'. For the purposes of clarity, I have chosen to focus on interpersonal skills, which I have defined above.

\section{Children with learning support needs}

The three children who are the subjects in the data I used had a variety of learning support needs. One had a diagnosis of ASD, another had a diagnosis of ADHD and a history of trauma, and a third (who I have called Sam) had no diagnosis but presented with challenges with interpersonal communication. Sam is also described in a vignette. Accordingly, some relevant literature on music therapy with children with these diagnoses and other social and behavioural challenges will be presented.

\section{Children with autism spectrum disorder (ASD)}

According to the Diagnostic and Statistical Manual of Mental Disorders (5th edition), ASD is a neuro-developmental disorder that is characterised by persistent deficits in social 
communication and social interaction across multiple contexts; and repetitive and restrictive play (American Psychiatric Association, 2013). These 'deficits' in social communication can include verbal communication challenges, such as not engaging in normal back-and-forth conversation, and a lack of response to, or initiation of, social interaction. Nonverbal communication deficits can include abnormal eye contact and body language, or a lack of understanding of gestures, or at the extreme end, a complete lack of facial expressions and communication. In terms of relationships, children with ASD can also have deficits in developing, understanding and maintaining relationships, for example, failing to adjust behaviour to suit different social contexts, or difficulty in making friends, or even the complete absence of interest in peer relationships.

More recently, autism has been described in terms of neurodiversity, rather than a disorder (Bakan, 2018; Baron-Cohen, 2017; Walker, 2014). The experiences of a person with autism are more chaotic and intense because of the higher levels of synaptic connectivity in the brain, and therefore the task of integrating sensory and cognitive experiences takes a lot of attention and energy (Walker, 2014). The brain of a child with autism interferes with the coding and making sense of 'messages', such as language and facial expression (Wigram, 1999), and sensory difficulties can make it more challenging to filter out irrelevant information (D. Rickson, personal communication, October 31, 2019). Because of the overwhelming amount of information being received and processed by the brain, and because this information can be stronger and less predictable, a child with autism needs to direct a lot of energy into attending to and making sense of this information; thus, he or she has less energy and attention to focus on social interaction (Walker, 2014). When children have difficulty interacting with peers, they might also experience social rejection. Through this lens, we might assume that sensory difficulties are core to ASD, and social and communication difficulties are secondary.

However ASD is described, it has been well documented that young children with ASD have challenges in joint attention skills and interpersonal communication (Schertz \& Odom, 2007; 
Thompson, McFerran \& Gold, 2014; Vaiouli, Grimmet \& Ruich, 2013). While neurotypical babies are primed for social interaction from birth and have their first 'conversations' in babbling with their caregivers (Wigram, 1999), babies with ASD have not been motivated to engage in reciprocal communication from infancy (Anglia Ruskin University, 2014; Thompson, McFerran \& Gold, 2014). Because a young child with autism may be confused by social 'messages' such as language and facial expression, social development can be affected and they may often retreat from social interaction (Bakan, 2018; Walker, 2014; Wigram, 1999). Thus, the normal pre-verbal conversational exchange is not developed, and so they do not move onto normal social interactions or forming social relationships; language delays can occur as a consequence. The world seems chaotic and confusing, and so children with ASD develop their own techniques to help them cope; these techniques can then turn into rituals or obsessions (Wigram, 1999). Such rituals could include self-stimulating behaviours, usually shortened to 'stimming', such as rocking back and forth or spinning an object repeatedly.

\section{$\underline{\text { Children with attention deficit hyperactivity disorder (ADHD) }}$}

Attention deficit hyperactivity disorder (ADHD) is a persistent pattern of inattention, hyperactivity and impulsivity that interferes with functioning or development (American Psychiatric Association, 2013; Shafiee-Kandjani et al., 2018). Symptoms are classified into inattention and hyperactivity or impulsivity, and children can exhibit predominantly inattentive symptoms, predominantly hyperactive or impulsive symptoms, or a combination of the three (ADHD New Zealand, 2018). Many children with ADHD have difficulties with social relationships, particularly with peers (de Boo \& Prins, 2007; Huang-Pollock et al., 2009; Mikami et al., 2017; Ozdemir, 2009; Zhang et al., 2017). Inattentive symptoms that may inhibit social relationships include: difficulty in sustaining attention, for example in play activities; appearing not to listen; being forgetful; and not following through on instructions (American Psychiatric Association, 2013). Impulsive and hyperactive symptoms that may inhibit social relationships include: interrupting or intruding in others' play; being perceived as difficult to keep up with because of being "on the go" constantly; running and climbing in inappropriate 
situations; being unable to play quietly and talking excessively; blurting out answers and not being able to wait for turns in conversation or in practical situations, such as waiting in line (American Psychiatric Association, 2013). Considering children with ADHD also have a high likelihood of co-morbid disorders such as oppositional defiance disorder, anxiety, and learning disorders (American Psychiatric Association, 2013; Glanzman \& Blum, 2007, as cited in Lesiuk, 2014), it is not hard to see why parents of children with ADHD may want to access targeted interventions to help their child.

Children with ADHD typically have an increased likelihood for antisocial behaviours; thus, interpersonal communication skills of these children deserve attention (Zhang et al., 2017). In contrast, children with positive social skills tend to have better self-esteem, self-confidence and self-control, higher academic achievement, more resistance to stress, and greater social cooperative skills (Barkley, 2006; Stormont, 2001). Also, negative social skills are often associated with mental health issues, social anxiety, and antisocial behaviour (Mcdougall et al., 2006; Parker \& Asher, 1987), learning difficulties, academic underachievement, and substance abuse (Mannuzza et al., 1998; Parker \& Asher, 1987; Young, 2000). Social skills training is a common intervention for children with ADHD; however there is limited evidence about the efficacy of this approach (Mikami et al., 2017).

\section{$\underline{\text { ADHD and trauma }}$}

There is also evidence suggesting a link between ADHD and trauma. Some studies found that children with ADHD have had more traumatic experiences (Koyuncu et al., 2016; ShafieeKandjani et al., 2018) and adverse childhood experiences (Semiz et al., 2012); however, research is still developing in this area. Children with ADHD are more likely to be maltreated (Prayez et al., 2012), and to suffer neglect and abuse, both physical and emotional (Ouyang et al., 2008; Sonnby et al., 2011). Indeed, American psychoanalyst Sugarman (2006) suggested that underlying trauma could contribute to the symptoms of ADHD. There are shared risk factors for ADHD and trauma, and the two conditions can present in a similar fashion (Daviss, 
2017). Traumatic symptoms, including avoidance, depression, hyperarousal, and reexperiencing, can easily be confused with ADHD symptoms (Daviss, 2017). Trauma may affect children's neurobiology and impair their functional ability or their response to standard ADHD treatments (Daviss, 2017). Trauma affects the developing brain of children and impairs their ability to learn (Carrion \& Wong, 2012).

\section{$\underline{\text { Undiagnosed or non-specific communication challenges }}$}

Children with challenges in interpersonal communication can have a variety of underlying conditions, such as global developmental delay, cerebral palsy, deafness, social anxiety, mental health issues, experiences of trauma, foetal alcohol spectrum disorder, and so on. Nearly any condition or disorder that a child has could lead to communication challenges as a secondary issue.

\section{Music therapy for children with learning support needs}

Music therapy is well established as an intervention for children with communication disorders (Oldfield, 2006; Wigram \& Gold, 2006). Music, a form of non-verbal communication that exists in all societies around the world, provides a way of developing interpersonal skills. In music therapy, the therapist uses the elements of music to communicate and share meanings (Wigram, Pedersen \& Bonde, 2002). Music provides opportunities to take turns, to attune to an object or person, and to create dialogue without using verbal language.

\section{Music therapy for children with ASD}

Music therapy interventions are often designed to increase positive social communication between children with ASD and the therapist, and between children with ASD and other children. Methods can include improvisation, receptive listening to pre-composed music, and songwriting, and these methods focus on relating, communicating and socialisation skills (Carpente \& LaGasse, 2015). Despite the increasing body of evidence, much of it positive, there is a lack of consistency in the findings of music therapy interventions with children with ASD. 
Results in a Cochrane review of randomised controlled trials (RCT) or controlled clinical trials looking at music therapy interventions showed that social communication skills, including nonverbal communication skills, may be enhanced for children with ASD (Geretsegger et al., 2006). A further systematic investigation involving ten clinical trials found a significant improvement in social interaction and social-emotional reciprocity for children with ASD (Geretsegger et al., 2014). Social interaction skills developed in music therapy interventions may also be transferred to outside the therapy context (Geretsegger et al., 2014; Gold, Wigram \& Elefant, 2006).

Gattino et al (2011), however, found no statistically significant differences in social communication for music therapy interventions for children with ASD. Similarly, Bieleninik et al (2017) in a recent large RCT, involving 364 children from nine different countries who participated in improvisational music therapy, found no improvements in ASD symptom reduction. Further investigation needs to be done as to why these interventions produced such different results, particularly since RCTs are held in such high esteem (Broder-Fingert et al., 2017; D. Rickson, personal communication, October 31, 2019). RCTs may not always be the best way to measure outcomes in music therapy (Kinn et al., 2013); in fact, neurodiverse communities often want their individual stories and their own voices to be included (Rickson et al., 2015; Walker, 2014), such as can happen in rich, descriptive qualitative studies.

Because of challenges in social communication for children with ASD, the musical exchanges in music therapy sessions may be a unique way of communicating for them. Group musicmaking may encourage listening skills and relational skills, including joint attention and social engagement, as well as promoting the enjoyment of playing music (Anglia Ruskin University, 2014; Spiro \& Himberg, 2016; Vaiouli, Grimmet \& Ruich, 2013). Indeed, while listening and waiting are among the key skills in all music-making, joint music-making lays foundations for non-verbal communication because the nature of making music relies on turn-taking and timing (Anglia Ruskin University, 2014; Wigram, 1999). 
Music therapy interventions can improve children's responses to and initiation of joint attention (Kim, Wigram \& Gold, 2009; LaGasse, 2014; Thompson, McFerran \& Gold, 2014), eye gaze, and two-way purposeful communication, such as turn-taking (Carpente, 2017; Thompson, McFerran \& Gold, 2014). Improvisation, with its scope for creativity, originality, freedom and flexibility, can include techniques such as mirroring, imitating or copying, matching, and dialoguing with the client to promote positive social communication (Wigram, 2004). A client's improvisations may parallel their normal everyday interactions (Smeijsters, 2003), which can provide practitioners with information on communicative issues that need to be addressed in therapy.

\section{Music therapy for children with ADHD}

While the literature on music therapy practice in special education is now substantial (McFerran, 2009), the literature on music therapy and ADHD was considered to be still developing at the turn of the century (Jackson, 2003) and is still sparse, and there is very little concerning the interpersonal skills of children with ADHD. Literature has focused on reducing the symptoms associated with ADHD, for example using background music to reduce hyperactivity (Cripe, 1986; Pratt et al., 1995), and using rock music to decrease inappropriate or disruptive behaviour (Wilson, 1976). Children with executive functioning deficits, including those with ADHD, have difficulties with listening, verbal memory, and organisation of written and verbal language (Mclnnes et al., 2003). Perhaps these executive functioning deficits, particularly in listening and attending to others, contribute to difficulties in relating to others.

Structure is important for children with ADHD, as the rhythm of music supports these children's internal organisation and they can then be more settled (Rickson, 2019; Rickson, 2006). The rhythm of music, in particular maintaining a steady beat, enables children to play together and to support each other during solos (Rickson, 2019). Music can also be containing for children with $A D H D$, and can catch their attention during chaotic moments and bring them back to their places, "where they were quiet and ready to attend more carefully to each other" (Rickson, 2019, para. 7). 


\section{Music therapy for children with other diagnoses or no diagnosis}

There are a number of international studies on music therapy interventions with children and young people without a specific medical diagnosis but with related interpersonal communication challenges. These include young people with intellectual and developmental disabilities (Rickson, 2019; Thompson \& Skewes McFerran, 2015); children who are 'at risk', including refugees, deprived children, bereaved children, children with behavioural or emotional issues (Carr \& Wigram, 2009; Porter et al., 2012); and children with social skills deficits (Gooding, 2011). Research results currently suggest that music therapy can be an effective intervention for children and adolescents with social, emotional and behavioural difficulties (Gooding, 2011; Porter et al., 2012), and that group music therapy may help with social skills for young people living with disabilities (Rickson, 2019). Although this collective research is promising, some of these studies have methodological weaknesses and therefore cannot provide clear-cut evidence about the efficacy of music therapy (Porter et al., 2012). In addition, because large-scale, randomised controlled trials are not possible with very few participants, many music therapy studies are small and therefore not generalisable (KnapikSzweda, 2015). This is particularly the case in New Zealand where the population is relatively small and a large number of participants may be difficult to find. Further research is warranted to strengthen the evidence that music therapy is an effective intervention for children with interpersonal communication challenges.

\section{Summary}

Music therapy is regarded as a promising intervention for children with learning support needs; however, in a field where there are often few participants in a single study because of small sample sizes, there is still research to be done, particularly with children without a medical diagnosis. Early research shows that music therapy interventions can improve social communication skills, such as turn-taking and joint attention. My research contributes to the literature by focusing on how music therapy can help in specific situations. 


\section{RESEARCH METHOD AND DESIGN}

The data for this project were the clinical data which were collected as part of my clinical work on placement at a full primary school. The school was a mainstream state school situated in a large city suburb. Students enrolled at the school were Years 0-8 (aged 5-12), and included several students with high needs who were funded by the Ongoing Resourcing Scheme (ORS). This enabled the school to receive funds from the Ministry of Education and some students to be supported by teacher aides throughout the school day. There were also a number of children with learning support needs identified by their teachers who did not receive ORS funding, including students who had ASD and ADHD, as well as students with behavioural and social issues, such as violent tendencies, a history of trauma, and other clinical needs.

The data set included clinical notes which were generated from richly detailed observations of music therapy sessions with these students, as part of my usual practice on placement. The sessions involved the children as individuals, in pairs, and in small groups participating in music sessions which included the use of instruments such as guitar, keyboard, voice and violin, as well as percussion and other instruments at the school.

After the data were collected, secondary analysis was employed to detect themes in the research data. Secondary analysis is described as "using existing data for a different purpose that is different than the original purpose for which the data was collected" (Bishop, 2011, para. 2). Existing data can be re-examined to ask new research questions about it. I then looked for emerging themes using thematic analysis, whereby themes and patterns were identified and analysed (Braun \& Clarke, 2006; Lapadat, 2010).

I had collected extensive notes in an electronic journal as part of my usual clinical practice: the notes were written as soon after sessions as I could manage and I ended up with approximately 70 A4 typed pages for each term. I had been careful in planning my sessions 
and in writing my notes afterwards to record all relevant information, and not focus just on interpersonal communication. Following Braun and Clarke's (2006) six-step process for thematic analysis, I began by familiarising myself with my data by reading over it several times. I then identified data that was relevant to my research question and began the process of coding, developing secondary codes, categories and themes. 


\section{ETHICS}

I abided by the Code of Ethics for the Practice of Music Therapy in New Zealand (Music Therapy New Zealand, 2012). This Code expresses the core ethical principles for the responsible practice of Music Therapy, and includes guidelines relating to relationships with clients, and privacy and confidentiality. The Code is also consistent with Te Tiriti o Waitangi, and is sensitive to Aotearoa New Zealand's multicultural society.

The Victoria University of Wellington Ethics Committee gave generic approval to the New Zealand School of Music (NZSM) Master of Music Therapy Programme ethical template for student research in NZSM 526 undertaken as observational studies, theoretical or case study research or action research (ref: \#22131, 2015). This study was judged to be low risk and consequently was not separately reviewed by any Human Ethics Committees. My practice was supervised by a visiting Registered Music Therapist, and the research was supervised by Dr Daphne Rickson, Senior Lecturer at the NZSM.

This research aligned with the principles of Victoria University's Te Tiriti o Waitangi Statute, specifically the principles of kawanatanga (governance), rangatiratanga (self-management), equality, reasonable cooperation, and redress. The key Treaty principles of partnership, participation and protection underpin the research. In practice, engaging with Māori means respecting their indigenous rights, protecting their individual and collective rights, and valuing their cultural practices and beliefs. I have endeavoured to uphold these principles.

I received written consent to use notes generated at the facility from my clinical liaison. The contributions of participants have been kept confidential, which means that I have kept the data safe and the responses of individuals are able to be identified by me only. Written data were protected by being kept in a locked file, and electronic data such as journal entries were password-protected, with access restricted to me. All data will be destroyed five years after the conclusion of this project, as per usual procedures for academic research conducted in education settings. 
I have also taken reasonable precautions to ensure that identifying details of participants are not included, including the real names of students and any background details, as well as identifying details of the school involved. I have had to be particularly careful about this with only three students as part of my study. Informed consent has been asked for separately where children are directly involved in my research, for example the case vignette. 


\section{ANALYSIS}

I chose to carry out a semantic thematic analysis as described by Braun and Clarke (2006). In this approach, the themes are identified at an explicit level and "the data have simply been organized to show patterns in semantic content" (Braun \& Clarke, 2006, p. 84), and then interpreted. This was appropriate because I was describing how I used music therapy to support interpersonal communication, and not going beyond this to look for underlying ideas and assumptions (Braun \& Clarke, 2006).

I began my analysis by highlighting all the data that related to interpersonal communication, keeping my question beside me at all times so that I had it forefront in my mind. Data that related to interpersonal communication included activities that promote listening and relating, joint attention, turn-taking, imitating, and sustaining a non-verbal dialogue. Sometimes data would seem relevant to interpersonal skills, but I had to remind myself that I was looking for how I supported the interpersonal skills of children, using music therapy. If I was not sure whether the datum was pertinent to my research question, I highlighted it in a different colour to review again later.

I began with the second term (ten weeks long), since I felt that I was getting into the thick of things by then and it was a good representation of the middle section of my placement. I initially thought that I would use the first term of data as well (ten weeks). After meeting with my supervisor, and feeling somewhat overwhelmed by the significant amount of data that I had highlighted, a decision was made to narrow my search down to focus on just three students. This seemed much more manageable, as many of the students I saw were concentrating on interpersonal skills, and it had felt as if I was highlighting nearly every paragraph.

I chose three quite different students, with whom I focused on interpersonal skills. For reasons of confidentiality, I will not give any background details for these students, but they will be described in general terms. One of them had a diagnosis of ASD and was classified as very 
high needs; another one had a diagnosis of ADHD and a history of trauma; and a third had no diagnosis but was referred because of a lack of emotional connection and difficulty in relating to others, as well as possible attachment issues. I knew that there was already a growing body of research on music therapy and children with autism, and so I chose these three students because I wanted to show how music therapy might work in a mainstream educational environment with students with varying diagnoses or no diagnosis to support interpersonal communication, and what the common themes might be in working with these diverse children.

After completing the task of highlighting all the data that related to three particular students for the second term, I had nearly 100 separate blocks of data and I realised that I then had enough data to answer my research question. Although there were other strategies and techniques that I employed in the third term, such as songwriting, I felt that I had enough data from this one term, particularly as the data were so rich and detailed.

I then re-examined the data, looking for ways in which I used music therapy to support the interpersonal communication of children with learning support needs. I looked for recurrent themes or relationships (Lapadat, 2010) in the coding process. I used inductive coding, so that I was searching for ideas to come from the data rather than applying a framework to the data (Hoskyns, 2013). Thus, I adopted an essentialist or realist approach focusing on a semantic approach to thematic analysis, as described by Braun and Clarke (2006).

I re-examined the data many times, using an Excel spreadsheet. For each block of data, I listed the methods, strategies and techniques used, and then noted the purpose of the activity, which eventually became my code. The methods I used were mostly song and improvisation. Other methods included activity, receptive listening, and verbal. Sometimes I thought that the data fitted into two categories; in which case, I would copy the data into a separate cell, and code it separately. 
I then copied the data into a separate spreadsheet and sorted it by purpose or code. I noted down each code and how many of each there were. At first, there were a lot of different codes (24). I looked at the codes again and renamed some of them to be consistent. I looked for how the data was linked, as coding involves linking alongside labelling (Saldaña, 2009, as cited in Hoskyns, 2013). Using coloured pencils, I decided which codes went together, for example, turn-taking and musical dialoguing seemed like a natural fit. I drew a box around each code if I thought it was most closely related to my research question. 


\section{RESULTS}

The themes I identified in analysing how I used music therapy to support the interpersonal communication skills of students are below. I sorted the data into five key themes as follows:

- I used the structure of songs and improvisation to encourage relating, listening and waiting, and joint attention.

- I used lyrics to encourage relating, listening and waiting, and joint attention.

- I followed the child's lead to enable them to make choices and to feel heard and empowered.

- I used improvisation to facilitate verbal conversations.

- I used familiar songs to support children's self-control and emotional regulation.

\section{Structure: songs and improvisation}

I used the structure of songs and improvisation to encourage relating, listening and waiting, and joint attention. Much of my practice was focused on encouraging relating through listening and waiting through various different methods, largely through songs and improvisation. I included joint attention with this code, as I felt that it was strongly linked with listening and waiting.

I provided structure within sessions by starting with a 'hello' song and ending with a 'goodbye' song. Structured songs provided a useful way of engaging children who needed boundaries and structure in sessions, and such boundaries are necessary for children to feel safe and to enable learning. Children became very familiar with the 'hello' song, and would be encouraged to acknowledge the other children and teacher aides in the room by singing hello to them. Beginning the 'hello' song would signal that the music therapy session was starting, and be more effective than using verbal language to tell them the session was starting. In the same 
way, the 'goodbye' song would signal the end of the session, at which point they knew it was time to leave the music room.

I used structured songs with steady beats that were inviting to join in with, and lyrics that also invited joining in. One example is Elton John's 'I'm still standing', for which I found a simple piano arrangement (arranger unknown) with a steady, repeated $A$ in the bass for most of the beginning of the song. At the chorus, "I'm still standing" is rejoined by "yeah, yeah, yeah" - an easy lyric to remember. The phrase also includes a pause to aid the anticipation of joining in. This example illustrates how this song worked in practice:

He started singing the beginning of "I'm still standing" - perfectly! ... I joined in, playing the repeated $A$ in the bass and then the bass line. He played the rhythm of the song with chord clusters, especially 'yeah yeah yeah' while miming the words.

I provided containment by playing the bass line while the student was interacting with me by playing chord clusters in the rhythm of the song, especially at the 'yeah yeah yeah' sections. Even if the student did not sing lyrics, we were communicating in a musical dialogue through this song. On other occasions, the student joined in by playing the rhythm on the drums and on the finger cymbals. Thus, the song invited participation through its rhythmic and structural cues.

I also used structured songs to facilitate interpersonal communication by practising turn-taking. One song that was pre-composed and had little space for improvisation was called 'Knock at the door'. The song invites percussive (knocking at the door) and sung responses ("can I come in?"). It uses anticipation ("let's open the door .... it's .... Anna!") to promote joint attention and turn-taking within the song (the student knocks at the door and then sings "can I come in?" while the therapist sings and plays the other parts) and also turn-taking between students. The pauses in parts of the song ("it's ...... Anna!") enabled the students to have the opportunity to join in and could be exaggerated to further aid anticipation. 
I used structured improvisation to facilitate activities such as 'echoing' each other's playing and passing the beat along to each other. These sorts of activities encouraged the students to relate to each other and to me, and I was able to model the musical behaviour expected. Relating through listening and waiting were also encouraged with an activity where the participants used their eyes to invite the next person to play in the improvisation. A student who sometimes struggled to relate to other people chose this activity a number of times, demonstrating to me that sometimes the simplest activities could be the most effective and that even older children enjoy simple relating activities.

The excerpt from my data below demonstrates how a simple passing the beat around activity encouraged relating through listening and waiting.

Passing the beat around the big frame drum worked REALLY well - it immediately engaged both of them and they both worked really well, listening and watching each other, and taking on the last person's dynamics and movements on the drum to pass on, clearly indicating through music when it was the next person's turn. This was great social cooperation and went on for quite a long time.

In the example below, I used free improvisation to encourage the children to engage in musical communication through listening. One child found it difficult so I focused on matching him musically.

We decided to do an improvisation without a theme... We began playing, with me on the guitar. Sam ${ }^{1}$ played quite atonally and slightly disordered and exploring up and down the keys. John was quite contained in his playing and tuned in with what I was doing. It felt a bit like an improvisation between me and John with Sam doing his own thing. I played chords and improvised some vocals on top, trying to tune in with what the others were doing as well as I could. I could hear John playing along with my

\footnotetext{
${ }^{1}$ Names have been changed
} 
rhythm but not Sam. At the end, John and I finished and I just waited instead of keeping on playing to see when Sam would notice that we had finished. After about 5-7 seconds, he brought it to a close, and we did the goodbye song.

There were other examples of activities designed to promote relating through listening and waiting that I felt did not work as well. When I used pre-recorded music with a beat (for example, the Fat Freddy's Drop song 'Ray ray', which contains a slow, steady beat), it was difficult for the children to hear it properly and they got out of time. One student found it particularly challenging to coordinate a beat, and I felt on reflection that live music could be more easily and flexibly adapted to his playing rather than pre-recorded music.

A structured improvisation where I used live music involved body percussion: I modelled three moves, such as slapping my thighs, clapping my hands, and clicking, and in the fourth beat, there would be space for each student to improvise a move. This activity encouraged listening and relating, as the students needed to listen carefully to the other students' moves so that they could repeat and join in.

\section{Lyrics}

I used lyrics to encourage relating, listening and waiting, and joint attention. The song referred to above ('Knock at the door') had the instructions within the lyrics of the song: "there's a knock at the door" to indicate it was someone's turn to knock at the door; the therapist sings "let's open the door"; the child sings "can I come in?"; the therapist sings "come in" and "everybody sing"; all participants then sing "come on in, come on in, everybody's welcome in!" The lyric instructions meant that I could emphasise certain phrases, such as "everybody sing" when a child found it a challenge to our relationship if anyone else sang. I managed this by using gestural cues, pointing to everyone in the room, and exaggerating "everybody sing", so that it was clear that the instruction was part of the song. I also made sure I respected his choice by saying that it would just be us for other songs: it felt important to hear him and give him some of what he wanted, but also to challenge his flexibility in terms of relationships. 
Other songs that had instructions within the lyrics of the song included a specially composed 'Play and stop' song, which had simple, repetitive lyrics: "I play and play and play and play and play and then I stop!" to encourage the children to play and then stop their instruments. I then changed the last word to "swap" when it was time to pass the instruments along to the next person. In this song, the children could direct the tempo and I would follow them; if they didn't start again, I sang "I ....", pausing on the dominant note as a harmonic cue to invite them to join. Cues such as this, as well as rhythmic, melodic, dynamic and timbre cues, can encourage dialoguing because they make it obvious that the music is coming to the end of a statement or asking a question (Wigram, 2004).

Improvisations were also used for musical dialoguing. Often I would use drums, sometimes a large one so that both the student and I were playing on the same instrument. Here is an example of how this worked in practice:

I got the big frame drum and we had an improvised conversation on it. He played a little bit, and I would answer. We would sometimes interrupt each other - well, he would mostly - but that is normal in a verbal dialogue, too. He used different parts of his hands - sometimes just one hand, which I tried to copy - and sometimes his fingers.

This excerpt shows how I was using turn-taking, musical dialoguing and mirroring as techniques within an improvisational method. For students who find verbal communication difficult, such as the student mentioned in the excerpt, musical dialoguing through improvisation could be an opportunity to really engage with someone else and be heard.

\section{Following a child's lead}

I followed the child's lead to enable them to make choices and to feel heard and empowered. Following a child's lead was a theme that I noticed strongly emerging from the data early on. 
These aspects of our sessions - following a child's lead, the child feeling heard, allowing choice, and empowerment - felt important because they are linked to interpersonal skills. When a child has had little choice, control or autonomy, the child may have lower self-esteem and be less intrinsically motivated (Deci et al., 1981), and thus interpersonal skills are likely to be stifled or underdeveloped. An environment where an adult's control is gradually reduced as the child's aspirations for autonomy increases is optimal for development (Eccles et al., 1991).

For a child to want to engage with other people, they will need to feel some level of being heard, otherwise they might not bother. In practice, this meant following a child's lead in improvisation, where I would mirror their playing. Sometimes I would follow their suggestion for an activity or song, and sometimes I would allow choice, such as the time I offered a child a green egg shaker and he instead took another identical green egg shaker!

I used songs and instructed the students to take turns 'directing', so that they would decide the speed of the song and what instruments the others would play. Children enjoyed having control over the music, and the delight on their faces was evident when they managed to stop and start the music or the movements by their own actions. I felt this was important in developing self-confidence and empowerment. Indeed, having the chance to make the music stop and start as well as choosing the dynamics of the music gives the child a chance to see how it feels to be in control.

\section{Facilitating verbal conversations}

I used improvisation to facilitate verbal conversations. Because most of the students I worked with were verbal, I used improvisational activities to facilitate conversation. For example, I used a drum 'rumbling' activity adapted from Faulkner (2017) where we would all beat fast on our drums if we agreed with a statement I said (such as, "rumble if you said something you shouldn't have this week"). I used an improvised rap to ask them in a beat what students did in their holidays, and they would answer in the beat I provided by slapping my thighs. 
To invite a genuine response, I sang a specially composed 'hello' song, during which I sang "Are you good? Are you bad? Are you ok?", and then gave space for students to answer. For students who were less verbal, I used gestures that they associated with good and bad, such as a thumbs up or thumbs down sign. Sometimes I would get an echolalic response, but sometimes I would receive what appeared to be a genuine response. Another specially composed hello song had the lyrics, "Are you feeling ok? Can you show me in your way?" and then I would stop singing and keep the guitar chords going while waiting for an answer from the student. In this way, I would use techniques of slowing and waiting, and structural cues in the music to invite responses.

Sometimes I needed to provide verbal prompts to enforce boundaries (such as saying the drum was "just for hands"), and sometimes I sang the goodbye song early to end the session if children were demonstrating inappropriate behaviour (such as swearing).

\section{$\underline{\text { Self-control and emotional regulation }}$}

I used familiar songs to support children's self-control and emotional regulation. A final theme related to self-control and emotional regulation. I thought quite hard about whether self-control and emotional regulation related to my research question. I decided that they did, because these skills can be learned from others and are essential for effective interpersonal communication. Indeed, emotional regulation helps us to manage difficult situations and thus allows us to function in our everyday lives (Essau et al., 2017); these skills can be developed in early childhood with interactive musical play, which could then reduce the risk of psychological challenges later on (Essau et al., 2017).

I used familiar songs to support children to regulate themselves, particularly children on the autistic spectrum, and to provide safety and comfort with something they knew. The structure and elements of the music enabled them to regulate themselves. For example, a child who was talking in jumbled language which I could not make sense of, appearing to be in his own 
world, was quickly regulated when I started beating on a woodblock while singing 'My Grandfather's Clock'. Before even a bar had passed, he had joined in and was matching my beating on his drum, and had appeared to calm down.

As an example of promoting self-control, I used claves to model playing loudly and softly while singing 'Bang bang, the sticks go bang' while the students followed me. Another song, 'Play and stop', was effective in promoting self-control because the lyrics invited children to stop playing their instruments, which might have been hard to do if they were particularly fascinated by an instrument. Self-control is thus linked to interpersonal skills because the children had to notice that others, including me, had stopped playing, and then control themselves to stop. The example below shows how an activity designed to promote self-control also regulated the children after an upsetting incident where another child had become dysregulated and was screaming and hitting herself.

I got out the sticks and we did 'bang, bang, the sticks go bang' - Simon made eye contact and played in time and loudly and softly in the right places - he showed great control and awareness of what was going on, particularly after such an upsetting incident. 


\section{CASE VIGNETTE}

This case vignette describes $\mathrm{Sam}^{2}$, a 9-year-old boy at a mainstream primary school (he turned 10 during the year). He was referred to music therapy because of a lack of emotional connection and difficulties in relating to others. In the classroom, his teacher described him as being behind his peers in most areas academically. His behaviour was occasionally violent in the playground. He lived with his mother, his stepfather, and his younger sister, who I also saw in music therapy. His father left some years prior and had a new family elsewhere; I understood that Sam had sporadic contact with his father.

When Sam began our sessions, he was at first shy and withdrawn. His body language was directed away from me, and he was verbally reticent. I felt unsure of how to relate to this boy, who I suspected was feeling singled out. I decided that goals should be related to self-control and self-expression, as well as positive ways of relating to others. For the reason of social relating, and because I thought it would make him feel more comfortable, I suggested that Sam bring a friend with him to subsequent sessions.

Sam gradually became more self-confident, and began to tell me about what they were doing in class on the way to the music room. He appeared to be engaged and attentive during sessions, and I described his eyes as 'lighting up'. Although he found it difficult to maintain a steady beat, he was focused and always tried hard. His music tended to be loud and dominant; as a boy who was big for his age, and who was often in trouble for violence, I felt that his music-making reflected his way of being in the world.

I used drums frequently, both in structured activities, and for improvisations. Rhythmic activities were used for connecting and binding players together, as rhythmic responses are often

\footnotetext{
${ }^{2}$ Names have been changed
} 
irresistible (Faulkner, 2017). Rhythm can help with stress by realigning homeostatic states (Perry \& Hambrick, 2008), as well as increasing focus and attention (Faulkner, 2017). A heartbeat pattern might remind children of the safety of the womb, and help them to feel relaxed (Faulkner, 2017), and I often used this heartbeat pattern as a basis for an improvised drumming activity.

After a greeting song, we often started our sessions with me modelling a beat pattern, which Sam struggled to replicate. However, he was incredibly creative, finding many different ways to play the drum (for example, turning it upside down or playing on the side), and using different parts of his body (for example, his elbows or the tips of his fingers). I introduced more free improvisation as time went on, and I noticed that Sam could sometimes be in his own world for these, seeming not to notice the music that his partner or I were playing. His music could be quite atonal and disordered, and improvisations often felt as though they were between his partner and me, with Sam doing his own thing.

In reflections in my journal, I wondered what else I could do to facilitate more interpersonal communication in music. I kept up musical activities that involved relating, and it was surprising to me how often Sam requested these. An improvisational activity that involved using our eyes to invite the next person to play seemed to really engage both students, and Sam returned to it several times.

Another activity I tried was getting the students to swap, so they tried to play like the other. My reflective journal recorded what happened:

I thought John imitated Sam quite well, even playing loudly and aggressively like Sam had with a beater, but it was clear that Sam hadn't listened as well, and he even admitted it as he ended up playing in his style again - loud, strong beats using the palm of his hands. 
I felt that being able to recognise that he hadn't listened well was a step in the right direction for Sam. In my other reflections, I noted that Sam seemed a bit "raw" and his music-making felt chaotic to me: I felt that he was not selfish or unaware of other people, but his internal rhythm seemed disordered. Although Sam had never been assessed or diagnosed with ADHD to my knowledge, I wondered if his inability to coordinate a steady beat, his inhibitory control, and his impaired information processing showed that he may have had an executive function deficit (Tamm et al., 2014). This deficit would have tied in with his behaviour in the playground, which was impulsive and occasionally violent. I felt that Sam's playing could represent possible trauma or attachment issues from his childhood, and that his personality was exemplified through his improvisations, just as Smeijsters (2003) suggested that a client's improvisations paralleled their everyday interactions. As a music therapist, however, I was interested in the client's presentation rather than a possible diagnosis, and so I felt that it would be helpful to draw on literature focusing on ADHD and executive function deficits.

Activities to encourage empathy and awareness of others seemed to have some impact with Sam, and by our final term together, I noticed that Sam's listening and relating skills were really developing. This excerpt from my journal recounts one of our improvisations:

Sam started in his usual way, where he played to himself, not really taking note of what was going on around him ... I picked up sounds that he was making, but made longer, more sustained notes on the violin as a containing structure ... he turned around once I started playing louder and more playfully - copying his sweeps up and down the keyboard. He turned around and smiled, as if he suddenly realised his playing was being copied and heard!

During this term, I also introduced writing raps as an activity to develop self-expression and collaborative skills. Sam was extremely engaged in this activity, coming up with themes and 
lyrics quickly and easily. One of the raps that Sam and his partner came up with went as follows:

We're so cool

we're on a rule

we should be the King Kong

banging on our chairs

We can fly like God

G.O.D.

we can fly out of this world

we should write a rap

like we are right now

we never laugh

like we just don't care

we can achieve anything

John is cool

we're on a rule

Sam's the best

like a giant guitar

Dow dow dow

Dow dow dow ...

Songwriting, or rap-writing, was a useful method to express who these two were as preteenage boys. Raps were something that they related to and enjoyed listening to. They collaborated to come up with the lyrics, and then decided to rap a line of the lyrics each, 
devising their own turn-taking activity. The activity demonstrated child empowerment, as I was following their lead with the lyrics they composed, and the lyrics expressed positive feelings about themselves ("we're so cool", "we can achieve anything", as well as complimenting each other on being "cool" or "the best"). I played a steady beat on the drum for structure and containment. Thus, the rap-writing activity demonstrated a number of themes that I used in music therapy regarding how I supported the interpersonal communication of children. 


\section{DISCUSSION}

This research shows how music therapy can support the interpersonal skills of children with learning support needs. Themes that I developed after analysing my data included encouraging relating through listening and waiting; turn-taking, including invitation to join and musical dialoguing; child empowerment, including following a child's lead, child feeling heard, choice, and empowerment; boundaries and structure; inviting response, including facilitating conversation and inviting genuine response; and self-control and regulation. Although I was not looking at improvement, but rather how I supported the children's interpersonal skills, it is interesting to note that the children's interpersonal skills were developed through methods such as song and improvisation. My research involved a small number of participants and it is therefore difficult to form generalisations; it does however show a variety of diagnoses and disorders as well as no diagnosis, and how music therapy interventions can be used with children with interpersonal communication challenges. In addition, the rich, detailed data that comes from this sort of qualitative analysis is a valuable addition to practice evidence.

\section{Encouraging relating}

I realised through this research that the relationships I developed with children were really important to foster interpersonal skills. It seemed fundamental to develop a relationship with these children first before we could then share experiences together, such as attending to an object together. One of the songs that I used to develop joint attention, 'Knock at the door', worked better the more we got to know each other. This meant that the anticipation could be increased when they knew the person waiting behind the door.

While I was encouraging the children's relating through listening and waiting, I realised that my skills in listening and waiting were just as important. This was particularly the case when I was working with students on the autistic spectrum: I often had to wait quite a while for a response, or over a series of sessions, before receiving a response in a song. For example, one child 
would often start singing a song after we had moved on. I felt that he needed more time to process the change to the next song. Sometimes he would sing a song from a previous session, or even from one a few weeks ago, which demonstrated to me how long processing can take with some children. With other children, I needed to wait over the course of several terms to see responses, and not just for children with ASD. With one child who presented with executive function deficits, I observed that he did not start listening and relating well until near the end of my practicum, after he had attended about 28 sessions.

\section{Music therapy techniques}

Although the scope of this study meant that I did not analyse techniques in detail, I realised during analysis that the data was rich with techniques, and thus I have devoted a section of this discussion to the techniques that I used to support interpersonal communication. I used techniques such as musical dialoguing, matching, modelling, mirroring, turn-taking, waiting, and using rhythmic, lyric, harmonic, tempo, structural and gestural cues to support the interpersonal communication skills of children. Some of these techniques are fluid, rather than distinct; for example, turn-taking is involved with musical dialoguing, however this is different from structured turn-taking in a musical activity.

Musical dialoguing refers to musical turn-taking between the client and therapist during improvisation. Wigram (2004) notes that some clients find it difficult to engage in turn-taking, particularly those clients who live with autism. I observed that children with ADHD also found it difficult to stop and listen long enough to take turns in musical dialoguing. Bruscia (1987) describes two therapeutic techniques for promoting dialogues: interjecting; and making space, and Wigram (2004) notes that modelling can help with this. Wigram (2004) also provides valuable examples of musical cues for therapists to enable dialoguing, such as harmonic, rhythmic, melodic, dynamic and timbre cues, to make it obvious that the music is coming to the end of a statement or asking a question. 
I used rhythmic, lyric, harmonic, tempo, structural and gestural cues to give the children space to answer. An example of a lyric cue that I used was in a greeting song where I sang, "how are you today?" I would also use a tempo cue by slowing the music down and waiting for an answer. In the Beatles song 'Help', I used the elements of harmony, rhythm, and tempo to invite a child to join in, singing "won't you please .... please ..." (the child sometimes joined in with "help me" at this point). In Elton John's song 'I'm still standing', the structural elements of the song invited joining in when the lyrics "I'm still standing" were sung: children then sang "yeah yeah yeah", or on other occasions they played the rhythm of those lyrics on an instrument. I used gestural cues such as doing a thumbs up or thumbs down sign during a 'how are you?' song, particularly with children who were non-verbal. I also used eye referencing (Wigram, 2004) during improvisations to invite the next student to join in.

All children need to learn how to take turns. Turn-taking can be more challenging for children with ASD and ADHD as their sensory and cognitive needs make it difficult to focus on social interactions (Rickson, 2019; Wigram, 2004). Turn-taking within music can provide an enjoyable and natural way to promote turn-taking: either in structured activities, or within freer improvisations. Musical activities can encourage students to be "patient and tolerant" while waiting for a turn (Rickson, 2019). I used structured turn-taking in musical activities, such as taking turns to knock at the door during a pre-composed song, and taking turns to direct a song or musical improvisation. These activities helped the children to acknowledge other people, to develop joint attention (such as turning towards the door to see who was knocking), and to feel like an important member of a group whose 'voice' was heard, because they knew that they would get a turn.

I also used modelling, mirroring and matching to support interpersonal skills. For example, I modelled listening and waiting when one child was showing their improvisation to me so that the other child would see positive interpersonal skills being demonstrated. I used mirroring doing exactly the same as the client musically at the same time - to enable the child to see his 
or her own behaviour in my music-making (Wigram, 2004). I also used matching - the improvisation of music that fits in with the client, maintaining the same musical elements such as tempo and dynamics (Wigram, 2004) - to support the children and make them feel heard.

\section{Following a child's lead}

I noticed that 'following a child's lead' or a 'child feeling heard' came through as a theme quite strongly during my analysis. Working in partnership with a child and respecting their rights is important to enable a child to develop autonomy alongside interpersonal skills (Alderson, 2008). These principles of participation and partnership align closely with Te Tiriti o Waitangi principles, and are a core feature of music therapy practice (Music Therapy New Zealand, 2012). Respecting a child as an equal partner sometimes involves following their lead, an approach that could be described as client-led or child-led. By simulating early parent-infant interaction through music, joint attention, turn-taking, and attunement are promoted (Kim, Wigram \& Gold, 2008). Further, by talking about things that a child is interested in, or playing along with their interests, children can 'tune-in' to an adult, and are therefore more likely to pay attention to other people (Lowry, 2016): this 'buy-in' leads them to be more involved with an activity. Following a child's interests also fosters engagement, communication and relatedness within a social context (Carpente, 2017).

In my practice, I observed that children were often more engaged if they directed the activities and I followed their lead. This might be as simple as them choosing something that I had planned before, or as free as a self-directed improvisation. Although I was often following their choice of activity, I still had to be mindful of their goals. For example, on one occasion a child with ADHD played me his own improvisation, but did not want me to play with him. While I was aware he may have wanted to remain in control because he has auditory sensitivity, I felt that he needed to be able to tolerate other people playing with him to develop his social skills, and 
so I gently challenged him on this through music. Eventually, he was able to tolerate me playing with him for brief periods.

\section{Providing boundaries, structure, and containment}

Children with autism and ADHD especially need consistent boundaries and find structure reassuring (Anglia Ruskin University, 2014; Rickson, 2019). In my practice, it took time to develop a balance between highly structured sessions, which appeared to engage some children more, and space for improvisation, which felt necessary for self-expression and developing flexibility.

My results were in line with Rickson's (2006) assertion that structure is important for children with ADHD, and that maintaining a steady beat seemed to 'settle' these children. When working with another young child with ADHD, he commented after an improvisation, "music makes me calm". Another child on the spectrum was in his own world, appearing to be fixated on something he had recently watched on a video; when I began to play steadily on the woodblock and sing a familiar song ('My Grandfather's Clock'), he was immediately roused and was drawn in to the music, and he began to beat a drum steadily himself.

\section{$\underline{\text { Inviting genuine responses }}$}

While some of my interventions were designed to facilitate conversation and invite genuine responses, these attempts often seemed unsuccessful. I would use drums and ask the children to 'rumble' if they agreed with a statement, and while they would rumble, they would not elaborate on the reasons for their rumbling. On a couple of occasions, I used the rumbling to facilitate conversation about violent episodes that had happened in the playground, and I was usually met with "that wasn't me" or "I don't want to talk about it". Perhaps this denial demonstrated a lack of success in my attempt to elicit any verbal response; however, in retrospect, I realised that adjusting my goal to processing these difficult feelings through musical expression seemed more manageable and less confrontational for the children than 
inviting conversation about them. In addition, I felt that some of them wanted to 'save face' in front of me, someone who they viewed as a sort of teacher and authority figure.

This reflection was backed up by reading Aigen's (2005) book on music-centred music therapy, who argues that a purely musical description can be a self-justifying clinical event, and that the motivation of the client is to participate in music, not to achieve some non-musical therapeutic goal (which the children were unaware of). Indeed, the therapeutic goal is the achievement of experiences and expression which are unique to music. In these cases, I felt that the musical experiences that I provided were more accessible and appropriate to achieve expression for these children.

Sometimes conversation through song happened quite naturally - such as a student with ADHD singing, "I wish I wasn't such an idiot" during an improvisation, and another time saying "everyone hates me". His behaviour during this seemed to agree with the literature suggesting that children with ADHD have lower self-esteem and difficulty making friends (de Boo \& Prins, 2007; Huang-Pollock et al., 2009; Mikami et al., 2017; Ozdemir, 2009; Zhang et al., 2017). During these occasions, I drew upon my training to listen carefully and observe (Hoskyns, 2002), offering unconditional positive regard (Rogers, 2007). Instead of negating the child's statements, which I imagined could make him feel not heard, I listened non-judgmentally, and reiterated his statements, for example, "you feel like you're an idiot". I used verbal language to try and draw the student out on how he felt, but I noted in my journal that it was unsuccessful as he did not engage any further in dialogue; and perhaps, as above, using music-centred music therapy was enough to process it, rather than trying to discuss it through verbal language afterwards.

At other times, responses were quite negative, such as a child who told me to "f* $\$ \#$ off" after a session during which he was increasingly dysregulated, and on other occasions perseverating on toilet talk. I felt that failing to adjust his behaviour was part of his social difficulties 
(American Psychiatric Association, 2013), and a sign that he was becoming dysregulated, rather than an attempt to seek attention or upset people. Despite these being negative responses, I wanted to provide space for the expression of negative emotions while maintaining the school's rules around appropriate behaviour. This meant that I discouraged swearing and needed to stop the sessions if it occurred repeatedly; I did not however react to these negative outbursts (such as reacting with shock or using an angry voice to tell the student off) as I felt that they were not targeted at me personally and I still wanted to provide unconditional positive regard for the child (Rogers, 2007).

\section{Self-control and emotional regulation}

I used familiar songs to support children's self-control and emotional regulation. Although I had not thought of self-control and emotional regulation being related to interpersonal skills, this was a theme that emerged in my data. When I thought about it, I realised that we begin to learn self-regulation from others so that we can cooperate together and participate in social activities. Self-regulation is a system that enables us to operate in our day-to-day life, managing challenging circumstances by modifying our emotional responses and returning us to a state of homeostasis (Sena Moore \& Hanson-Abromeit, 2015). Children can begin to develop emotional regulation through playful musical activities, which have been shown to demonstrate a marked improvement in emotional regulation scores, and can alleviate the risks of psychological challenges when they are older (Sena Moore \& Hanson-Abromeit, 2015). If children are not able to regulate themselves when they experience strong negative emotions, they are more likely to externalise these and thus react with inappropriate behaviour (Ozdemir, 2009).

My experience with other children at the school at which I was on placement indicated that familiar songs may support their emotional regulation. In one example when a child was extremely distressed, she was eventually able to calm to the steady constant pulse of a greetings song, in a group setting. However, when children are being seen individually 
improvisation techniques can also support emotional regulation, because they provide opportunities for musical expression and increased agency. 


\section{LIMITATIONS}

This research was conducted while I was a student on placement (approximately eight months). I needed to choose a topic that was relatively broad to ensure that I would have enough data to analyse through secondary analysis. In addition, there was less than a month between starting the placement and submitting a research proposal, which did not give much time to get to know the students thoroughly and the issues that they might need addressed through therapy.

Because I ended up with such a large amount of data, a decision was made to focus on three students. With just three students in my study, I was still able to answer my research question about how I supported interpersonal communication. In addition, in this qualitative research, I was able to use rich descriptions to 'tell a story' more effectively than I would have been able to with a large number of students. I could have chosen to focus on whether I used different techniques for different children, depending on their diagnosis and/or various needs, but instead I chose not to do a comparison for reasons of clarity and time. Future research could identify whether different approaches and themes would be drawn upon for students with specific learning needs.

In essence, my research question - how I supported the children's interpersonal communication - dictated the form of research (qualitative). Although there were other forms of analysis that I could have chosen to analyse the data, such as grounded analysis, I chose semantic thematic analysis because it was appropriate, because it was recommended for students and beginning researchers (Braun \& Clarke, 2006), and because there was a clear process. These practical considerations are important to acknowledge in conducting research. 


\section{CONCLUSION}

The rich description in this research will be helpful to understand how music therapists work to support interpersonal communication skills for children with learning support needs. Focusing on three students with various learning support needs, including ASD, ADHD, and a student without any formally diagnosed condition, I detected themes in my data, including using the structure of songs and improvisation to encourage relating, listening and waiting, and joint attention; using lyrics to encourage relating, listening and waiting, and joint attention; following a child's lead to enable them to make choices and to feel heard and empowered; using improvisation to facilitate verbal conversations; and using familiar songs to support children's self-control and emotional regulation.

Finally, the evidence showing how music therapy supports children with learning support needs, including those without any diagnosis, still warrants further investigation, particularly in New Zealand where research is scant. A future study showing music therapy interventions with children with different diagnoses and needs and how these interventions might have been different would be a promising future research direction. 


\section{APPENDIX 1: FACILITY CONSENT FORM}

20 February 2019

\section{Dear}

As part of my second year of a Master of Music Therapy in which I am enrolled, I am required to carry out a research project at my placement, the results of which will be presented in a written exegesis at the end of the year. This letter is to formally request the permission for the use of clinical data collected on my placement. The research will be supervised by Dr Daphne Rickson, Senior Lecturer and Coordinator of Clinical Programmes in Music Therapy at the New Zealand School of Music. Because it is low-risk research, ethics approval has already been granted (Ethics Application ref: \#22131, 2015). In addition, I will abide by the Code of Ethics for the Practice of Music Therapy in New Zealand.

I am also required to include a 'vignette' as part of our research, and I will ask for informed consent separately from a student's family for this in due course.

Please sign both copies of this letter, and return one to me, to indicate that permission is granted from

Let me know if you have any concerns about this, or don't hesitate to contact Dr Daphne Rickson.

With kind regards,

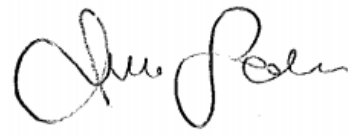

\section{Anna Sedcole}

Music Therapy student

New Zealand School of Music

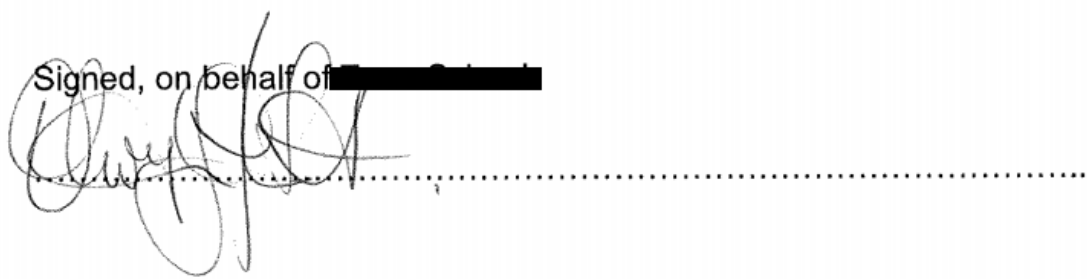




\title{
APPENDIX 2: CASE VIGNETTE CONSENT FORMS
}

\section{MUSIC THERAPY PROGRAMME (MMusTher)}

\author{
Case Vignette - Information and Consent Form
}

Kia ora. I am Anna Sedcole, the music therapy student currently working a

As part of the requirements for my music therapy clinical placement I am required to complete an exegesis, illustrated by a vignette from my clinical work. I am writing to ask if I can describe the work I have done with

The exegesis including the case vignette will be sent for examination. The examiners will be both internal and external to the New Zealand School of Music, Victoria University of Wellington. The exegesis will also be published in the Victoria University of Wellington library, in hard copy and as an online resource.

If you agree, the case vignette is likely to include background information abou Anonymity will be protected whenever possible, with all information that might identify and/or the name of the facility being removed. I will use a pseudonym when describing will not use photographs, audio, or video material in my case vignette.

Please take time to think about this, and ask any questions you might have (I can be contacted by email when you are sure you agree that I can write about n my case vignette, please sign both copies of this letter, keep one, and give one back to me. If you would like a copy of the case vignette and/or exegesis, it will be provided for you after the work has been completed and examined, following the conclusion of my placement.

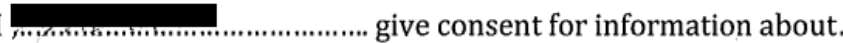
case vignette described above.

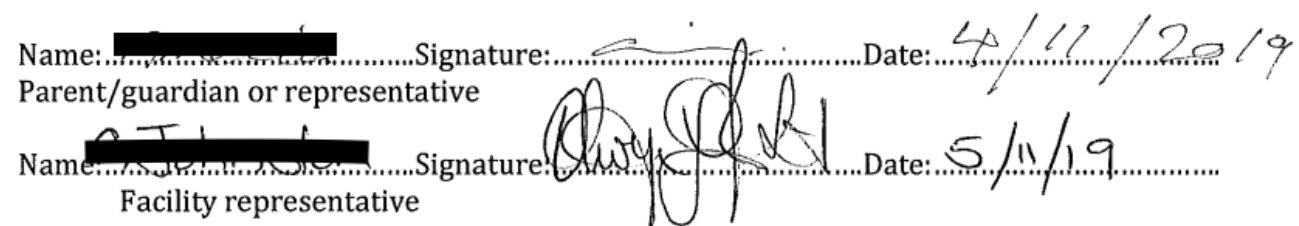

This consent expires on 14 December 2019 and may be withdrawn at any time by contacting the Music Therapy Programme Director at 4635233 x35807 


\section{APPENDIX 3: CODING EXAMPLE}

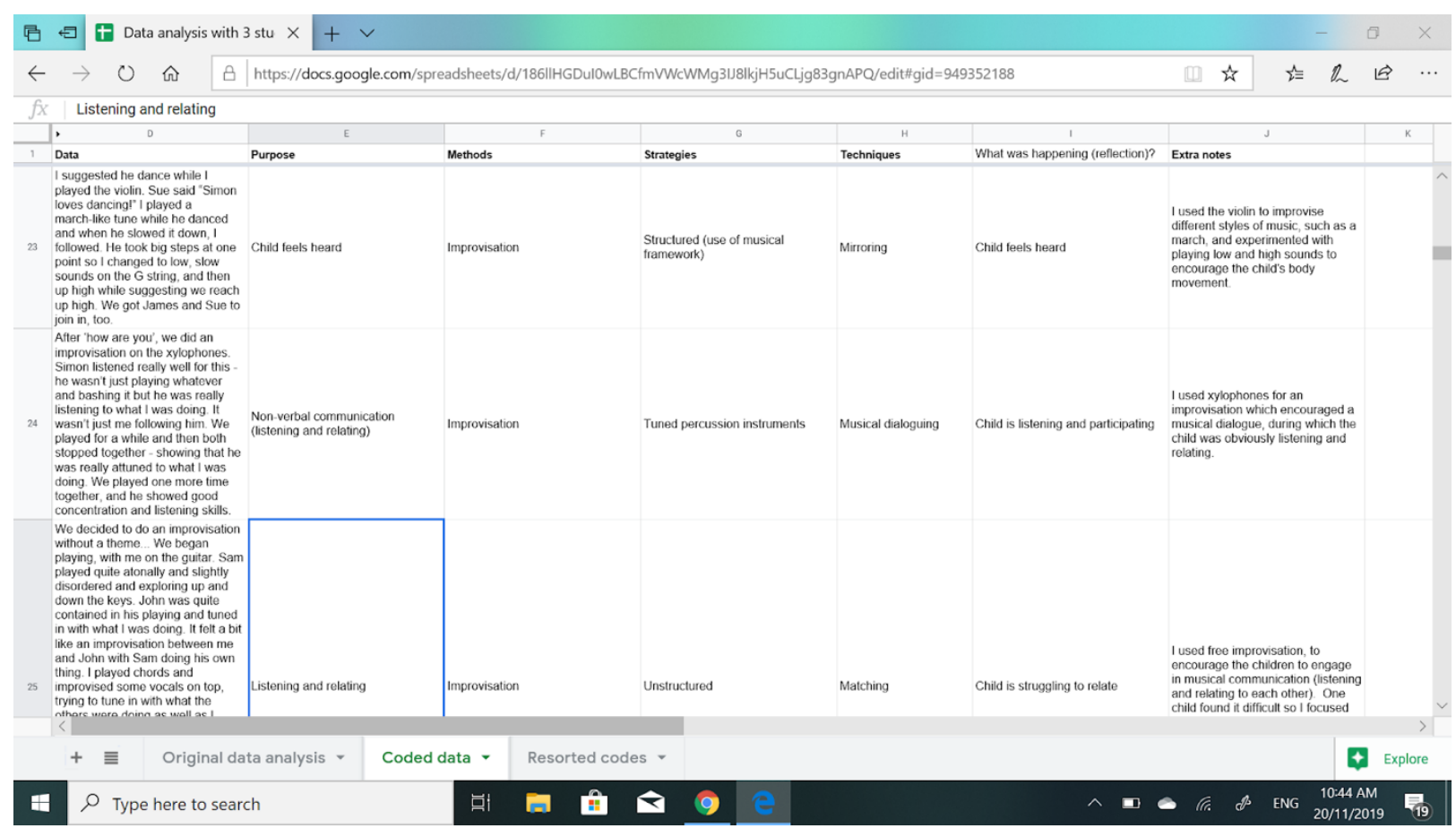

*names have been changed 


\section{REFERENCES}

ADHD New Zealand (2018). What is ADHD? Retrieved November 26, 2019, from https://www.adhd.org.nz/what-is-adhd.html

Aigen, K. (2005). Music-centred music therapy. Gilsum, NH: Barcelona.

Alderson, P. (2008). Young children's rights: Exploring beliefs, principles and practice (2nd ed.). London: Jessica Kingsley.

American Psychiatric Association (2013). Diagnostic and statistical manual of mental disorders (5th ed.). Washington, DC: American Psychiatric Association.

Anglia Ruskin University (2014, July 30). Music therapy for children on the autism spectrum at Anglia Ruskin University [Video]. YouTube.

https://www.youtube.com/watch?v=9P14eZZEG64\&t=398s

Bakan, M. B. (2018). Speaking for ourselves: Conversations on life, music, and autism. New York: Oxford University Press.

Barkley, R. A. (2006). Attention-deficit hyperactivity disorder: A handbook for diagnosis and treatment (3rd ed.). New York: Guilford Press.

Baron-Cohen, S. (2017). Editorial perspective: Neurodiversity - A revolutionary concept for autism and psychiatry. Journal of Child Psychology and Psychiatry, 58(6), 744-747. https://doi.org/10.1111/jcpp.12703 
Bieleninik, Ł., Geretsegger, M., Mössler, K., Assmus, J., Thompson, G., Gattino, G., Elefant, C., Gottfried, T., Igliozzi, R., Muratori, F., Suvini, F., Kim, J., Crawford, M., Odell-Miller, H., Oldfield, A., Casey, O., Finnemann, J., Carpente, J., \& Park, A.-L. et al. (2017). Effects of improvisational music therapy vs enhanced standard care on symptom severity among children with autism spectrum disorder: The TIME-A randomized clinical trial. JAMA, 318(6), 525-535. https://doi.org/10.1001/jama.2017.9478

Bishop, L. (Academic). (2011). What is secondary analysis of qualitative data? [Streaming video]. Retrieved from Sage Research Methods. https://doi.org.10.4135/9781412995573

Braun, V., \& Clarke, V. (2006). Using thematic analysis in psychology. Qualitative Research in Psychology, 3(2), 77-101. https://doi.org/10.1191/1478088706qp063oa

Broder-Fingert, S. Feinberg, E., \& Silverstein, M. (2017). Music therapy for children with autism spectrum disorder. JAMA, 318(6), 523-524. https://doi.org/10.1001/jama.2017.9477

Bruscia, K. E. (2005). Designing qualitative research. In B. L. Wheeler (Ed.), Music Therapy Research (2nd ed.) (pp. 129-37). Gilsum, NH: Barcelona.

Bruscia, K. E. (1995). The process of doing qualitative research. In B. L. Wheeler (Ed.), Music therapy research: Quantitative and qualitative perspectives (pp. 389-400). Gilsum, NH: Barcelona.

Bruscia, K. E. (1987). Improvisational models of music therapy. Springfield: Charles C. Thomas Publications.

Carpente, J. A. (2017). Investigating the effectiveness of a developmental, individual difference, relationship-based (DIR) improvisational music therapy program on social communication 
for children with autism spectrum disorder, Music Therapy Perspectives, 35(2), 160-174. https://doi.org/10.1093/mtp/miw013

Carpente, J. A., \& LaGasse, A. B. (2015). Music therapy for children with autism spectrum disorder. In B. L. Wheeler (Ed.) Music therapy handbook (pp. 290-301). New York: Guilford Press.

Carr, C., \& Wigram. T. (2009). Music therapy with children and adolescents in mainstream schools: A systematic review. British Journal of Music Therapy, 23(1), 3-18. https://doi.org/10.1177/135945750902300102

Carrion, V. G., \& Wong. S. S. (2012). Can traumatic stress alter the brain? Understanding the implications of early trauma on brain development and learning. Journal of Adolescent Health, 51(2), 23-28. https://doi.org/10.1016/j.jadohealth.2012.04.010

Cripe, F. (1986). Rock music as therapy for children with attention deficit disorder: An exploratory study. Journal of Music Therapy, 23(1), 30-37. https://doi.org/10.1093/jmt/23.1.30

Daviss, W. B. (2017). Trauma-related moodiness in children with attention-deficit/hyperactivity disorder. Journal of the American Academy of Child \& Adolescent Psychiatry, 56(10), 95. https://doi.org/10.1016/j.jaac.2017.07.372

de Boo, G. M. \& Prins., P. J. M. (2007). Social incompetence in children with ADHD: Possible moderators and mediators in social-skills training. Clinical Psychology Review, 27(1), 7897. https://doi.org/10.1016/j.cpr.2006.03.006 
Deci, E. L., Schwartz, A. J., Sheinman, L., \& Ryan, R. M. (1981). An instrument to assess adults' orientations toward control versus autonomy with children: Reflections on intrinsic motivation and perceived competence. Journal of Educational Psychology, 73(5), 642650. https://doi.org/10.1037/0022-0663.73.5.642

Eccles, J. S., Miller Buchanan, C., Flanagan, C., Fuligni, A., Midgley, C., \& Yee, D. (1991). Control versus autonomy during early adolescence. Journal of Social Issues, 47(4), 5368. https://doi.org/10.1111/j.1540-4560.1991.tb01834.x

Essau, C., Leblanc, S., \& Ollendick, T. H. (2017). Emotion regulation and psychopathology in children and adolescents (1st ed). Oxford: Oxford University Press.

Faulkner, S. (2017). Rhythm to recovery: A practical guide to using percussion, voice and music for social and emotional development. London: Jessica Kingsley.

Gattino, G. S., Riesgo, R. D. S., Longo, D., Leite, J. C. L., \& Faccini, L. S. (2011). Effects of relational music therapy on communication of children with autism: A randomized controlled study. Nordic Journal of Music Therapy 20(2), 142-54. https://doi.org/10.1080/08098131.2011.566933

Geretsegger, M., Elefant, C., Mössler, K. A., \& Gold, C. (2006). Music therapy for people with autism spectrum disorder. Cochrane Database of Systematic Reviews, 2. https://doi.org/10.1002/14651858.CD004381.pub3

Geretsegger, M., Elefant, C., Mössler, K. A., \& Gold, C. (2014). Music therapy for people with autism spectrum disorder. Cochrane Database of Systematic Reviews. 6. https://doi.org/10.1002/14651858.CD004381.pub3 
Gold, C., Wigram, T., \& Elefant, C. (2006). Music therapy for autistic spectrum disorder. Cochrane Database Of Systematic Reviews, 2. https://doi.org/10.1002/14651858.CD004381.pub2

Gooding, L. F. (2011). The effect of a music therapy social skills training program on improving social competence in children and adolescents with social skills deficits. Journal of Music Therapy, 48(4), 440-62. https://doi.org/10.1093/jmt/48.4.440

Hoskyns, S. (2013). Enabling the curious practitioner: perceptions on the integration of research and practice in the education of music therapy students at masters' level. Victoria University of Wellington.

Hoskyns, S. (2002). Evolving a capacity for wondering: The development of observation and listening skills. In L. Bunt \& S. Hoskyns (Eds.), The handbook of music therapy (pp. 16788). London: Routledge: Taylor and Francis Group.

Huang-Pollock, C. L., Mikami, A. Y., Pfiffner, L., \& McBurnett, K. (2009). Can executive functions explain the relationship between attention deficit hyperactivity disorder and social adjustment? Journal of Abnormal Child Psychology, 37(5), 679-691.

https://doi.org/10.1007/s10802-009-9302-8

Hunt, A. (2016). First-person research. In B. L. Wheeler \& K. M. Murphy (Eds.), Music therapy research (3rd ed., pp. 453-467). Dallas, TX: Barcelona Publishers.

Jackson, N. A. (2003). A survey of music therapy methods and their role in the treatment of early elementary school children with ADHD. Journal of Music Therapy, 40(4), 302-323. https://doi.org/10.1093/jmt/40.4.302 
Kho, H. C. (2011). Promoting communication and socialisation in music therapy for children with cerebral palsy. Wellington, NZ: Victoria University of Wellington.

Kim, J., Wigram, T., \& Gold, C. (2009). Emotional, motivational and interpersonal responsiveness of children with autism in improvisational music therapy. Autism, 13(4), 389-409. https://doi.org/10.1177/1362361309105660

Kim, J., Wigram, T., \& Gold, C. (2008). The effects of improvisational music therapy on joint attention behaviors in autistic children: A randomized controlled study. Journal of Autism and Developmental Disorders, 38(9), 1758-1766. https://doi.org/10.1007/s10803-0080566-6

Kinn, L., Holgersen, H., Ekeland, T., \& Davidson, L. (2013). Metasynthesis and bricolage: An artistic exercise of creating a collage of meaning. Qualitative Health Research, 23(9), 1285-1292. https://doi.org/10.1177/1049732313502127

Knapik-Szweda, S. (2015). The effectiveness and influence of vocal and instrumental improvisation in music therapy on children diagnosed with autism. Pilot study. Journal of Education Culture and Society, 1, 153-166. https://doi.org/10.15503/jecs20151.153.166

Koyuncu, A., Çelebi, F., Ertekin, E., Kök, B. E., \& Tükel, R. (2016). Attention deficit and hyperactivity in social anxiety disorder: Relationship with trauma history and impulsivity. ADHD Attention Deficit and Hyperactivity Disorders, 8(2), 95-100. https://doi.org/10.1007/s12402-016-0189-2

LaGasse, A. B. (2014). Effects of a music therapy group intervention on enhancing social skills in children with autism. Journal of Music Therapy, 51(3), 250-75. https://doi.org/10.1093/jmt/thu012 
Lapadat, J. C. (2010). Thematic analysis. In A. J. Mills, G. Durepos \& E. Wiebe (Eds.), Encyclopedia of case study research (pp. 925-927). Sage Research Methods. https://doi.org/10.4135/9781412957397.n342

Lesiuk, T. (2014). Music perception ability of children with executive function deficits. Psychology of Music, 43(4), 530-544. https://doi.org/10.1177/0305735614522681

Lowry, L. (2016). "Tuning in” to others: How young children develop theory of mind. The Hanen Centre. Retrieved November 26, 2019, from http://www.hanen.org/HelpfulInfo/Articles/Tuning-In-to-Others-How-Young-Children-Develop.aspx

Malloch, S., \& Trevarthen, C. (2009). Communicative musicality: Exploring the basis of human companionship. Oxford: Oxford University Press.

Mannuzza, S., Klein, R. G., Bessler, A., Malloy, P., \& LaPadula, M. (1998). Adult psychiatric status of hyperactive boys grown up. American Journal of Psychiatry, 155(4), 493-98. https://doi.org/10.1176/ajp.155.4.493

Matney, B. (2019). A knowledge framework for the philosophical underpinnings of research: Implications for music therapy. Journal of Music Therapy, 56(1), 1-29. https://doiorg.helicon.vuw.ac.nz/10.1093/jmt/thy018

Mcdougall, P., Hymel, S., Vaillancourt, T., \& Louise, M. (2006). The consequences of childhood peer rejection. Oxford Scholarship Online. https://doi.org/10.1093/acprof:oso/9780195130157.001.0001 
McFerran, K. (2009). Quenching a desire for power: the role of music therapy for adolescents with ADHD. Australasian Journal of Special Education, 33(1), 72-83. Retrieved from https://search.informit.com.au/documentSummary;dn=525078111670096;res=IELHSS

McFerran, K. S., \& Silverman, M. J. (2018). A guide to designing research questions for beginning music therapy researchers. Silver Spring, MD: The American Music Therapy Association.

Mclnnes, A., Humphries, T., Hogg-Johnson, S., \& Tannock, R. (2003). Listening comprehension and working memory are impaired in attention-deficit hyperactivity disorder irrespective or language impairment. Journal of Abnormal Child Psychology, 31(4), 427-443. https://doi.org/10.1023/A:1023895602957

Mikami, A. Y., Smit, S., \& Khalis, A. (2017). Social skills training and ADHD—What works? Current Psychiatry Reports, 19(12), 93. https://doi.org/10.1007/s11920-017-0850-2

Ministry of Education (n.d.) Learning support needs. Ministry of Education. Retrieved October 29, 2019, from https://parents.education.govt.nz/learning-support/learning-support-needs/

Music Therapy New Zealand (2012). Code of ethics for the practice of music therapy in New Zealand. Retrieved November 25, 2019, from https://www.musictherapy.org.nz/wpcontent/uploads/2019/01/PS1Code-of-Ethics-Sep-2012.pdf

O'Callaghan, C. (2012). Grounded theory in music therapy research. Journal of Music Therapy, 49(3), 236-277. http://doi.org/10.1093/jmt/49.3.236

O'Callaghan, C., Petering, H., Thomas, A., \& Crappsley, R. (2009). Dealing with palliative care patients' incomplete music therapy legacies: Reflexive group supervision research. Journal 
of Palliative Care, 25: 197-205.

\section{https://doi-org.helicon.vuw.ac.nz/10.1177/082585970902500307}

Oldfield, A. (2006). Interactive music therapy - A positive approach: Music therapy at a child development centre. London: Jessica Kingsley.

Ouyang, L., Fang, X., Mercy, J., Perou, R., \& Grosse, S. D. (2008). Attentiondeficit/hyperactivity disorder symptoms and child maltreatment: A population-based study. The Journal of Pediatrics, 153(6), 851-856. https://doi.org/10.1016/j.jpeds.2008.06.002

Ozdemir, S. (2009). Peer relationship problems of children with AD/HD: Risk factors and new directions in interventions. Australasian Journal of Special Education, 33(1), 42-59. Retrieved from https://search.informit.com.au/fullText;dn=525022212756322;res=IELHSS

Parker, J. G., \& Asher, S. R. (1987). Peer relations and later personal adjustment: Are lowaccepted children at risk? Psychological Bulletin, 102(3), 357-389. https://doi.org.helicon.vuw.ac.nz/10.1037/0033-2909.102.3.357

Pasiali, V. (2012). Supporting parent-child interactions: Music therapy as an intervention for promoting mutually responsive orientation. Journal of Music Therapy, 49(3), 303-334. https://doi.org/10.1093/jmt/49.3.303

Perry, B. D., \& Hambrick, E. P. (2008). The Neurosequential Model of Therapeutics. Reclaiming Children and Youth, 17(3), 38-43.

Porter, S., Holmes, V., McLaughlin, K., Lynn, F., Cardwell, C., Braiden, H.-J., Doran, J., \& Rogan, S. (2012). Music in mind, a randomized controlled trial of music therapy for young people with behavioural and emotional problems: Study protocol. Journal of Advanced 
Nursing, 68(10), 2349-2358. https://doi-org.helicon.vuw.ac.nz/10.1111/j.1365-

2648.2011.05936.x

Pratt, R. R., Abel, H. H., \& Skidmore, J. (1995). The effects of neurofeedback training with background music on EEG patterns of ADD and ADHD children. International Journal of Arts Medicine, 4, 24-31.

Prayez, F., Wodon, I., Linkowski, S., \& Van Hyfte, P. (2012). Trouble déficitaire de l'attention avec hyperactivité (TDAH) et maltraitance durant l'enfance: Revue de la littérature. Revue Medicale de Bruxelles, 33(2), 75-86.

Rickson, D. J. (2019). Working in music with adolescents who experience disability. In K. McFerran, P. Derrington, \& S. Saarikallio (Eds.), Handbook of music, adolescents, and wellbeing. Oxford Scholarship Online.

https://doi.org/10.1093/oso/9780198808992.003.0013

Rickson, D. J. (2006). Instructional and improvisational models of music therapy with adolescents who have attention deficit hyperactivity disorder (ADHD): A comparison of the effects on motor impulsivity. Journal of Music Therapy, 43(1), 39-62. https://doi.org/10.1093/jmt/43.1.39

Rogers, C. R. (2007). The necessary and sufficient conditions of therapeutic personality change. Psychotherapy, 44(3), 240-248._http://dx.doi.org.helicon.vuw.ac.nz/10.1037/00333204.44.3.240

Schertz, H. H., \& Odom, S. L. (2007). Promoting joint attention in young children with autism: A parent-mediated developmental model. Journal of Autism and Developmental Disorders, 37(8), 1562-1575. https://doi.org/10.1007/s10803-006-0290-z 
Semiz, U. B., Cengiz, F. F., \& Oner, O. (2012). Adult attention deficit hyperactivity disorder and trauma. Klinik Psikofarmakoloji Bulteni; Istanbul, 22(1), S29.

Sena Moore, K., \& Hanson-Abromeit, D. (2015). Theory-guided therapeutic function of music to facilitate emotion regulation development in preschool-aged children. Frontiers in Human Neuroscience, 9, 572-572. https://doi.org/10.3389/fnhum.2015.00572

Shafiee-Kandjani, A., Noorazar, S., Aslanabadi, S., Rashedi, N., Dadkhah, M., JafarzadehGharehziaaddin, M. (2018). The relationship between attention-deficit/ hyperactivity disorder and trauma in adolescents. Journal of Emergency Practice and Trauma, 4(1), 1823. https://doi/org/10.15171/jept.2017.23

Smeijsters, H. (2003). Forms of feeling and forms of perception: The fundamentals of analogy in music therapy. Nordic Journal of Music Therapy, 12(1), 71-85. https://doi.org/10.1080/08098130309478075

Sonnby, K., Åslund, C., Leppert, J., \& Nilsson, K. (2011). Symptoms of ADHD and depression in a large adolescent population: Co-occurring symptoms and associations to experiences of sexual abuse. Nordic Journal of Psychiatry, 65(5), 315-322. https://doi.org/10.3109/08039488.2010.545894

Spiro, N., \& Himberg, T. (2016). Analysing change in music therapy interactions of children with communication difficulties. Philosophical Transactions of the Royal Society of London. Series B, Biological Sciences, 371. https://doi.org/10.1098/rstb.2015.0374 
Stormont, M. (2001). Social outcomes of children with AD/HD: Contributing factors and implications for practice. Psychology in the Schools, 38(6), 521.

https://doi.org/10.1002/pits.1040

Sugarman, A. (2006). Attention deficit hyperactivity disorder and trauma. The International Journal of Psychoanalysis, 87(1), 237-241._https://doi.org/10.1516/F2BD-QXEU-NENXQL3N

Tamm, L., Nakonezny, P. A., \& Hughes, C. W. (2014). An open trial of a metacognitive executive function training for young children with ADHD. Journal of Attention Disorders, 18(6), 551-559. https://doi.org/10.1177/1087054712445782

Tate, J. A., \& Happ, M. B. (2018). Qualitative secondary analysis: A case exemplar. Journal of Pediatric Health Care, 32(3), 308-312. https://doi.org/10.1016/j.pedhc.2017.09.007

Thompson, G. (2012). Family-centered music therapy in the home environment: Promoting interpersonal engagement between children with autism spectrum disorder and their parents. Music Therapy Perspectives, 30(2), 109-116._https://doi.org/10.1093/mtp/30.2.109

Thompson, G., McFerran, K., \& Gold, C. (2014). Family-centred music therapy to promote social engagement in young children with severe autism spectrum disorder: A randomized controlled study. Child: Care, Health and Development, 40(6), 840-852. https://doi.org/10.1111/cch.12121

Thompson, G. A., \& Skewes McFerran, K. (2015). Music therapy with young people who have profound intellectual and developmental disability: Four case studies exploring communication and engagement within musical interactions. Journal of Intellectual \& Developmental Disability, 40(1), 1-11. https://doi.org/10.3109/13668250.2014.965668 
Vaiouli, P., Grimmet, K., \& Ruich, L. J. (2013). 'Bill is now singing': Joint engagement and the emergence of social communication of three young children with autism. Autism: The International Journal of Research and Practice, 19(1), 73-83.

https://doi.org/10.1177/1362361313511709

Walker, N. (2014). What is autism? Neurocosmopolitanism: Dr Nick Walker's notes on neurodiversity, autism, and cognitive liberty. Retrieved November 6, 2019, from https://neurocosmopolitanism.com/what-is-autism/

Wheeler, B. L. (2005). Music therapy research (2nd ed). Gilsum, N. H.: Barcelona.

Wheeler, B. L., \& Kenny, C. (2005). Principles of qualitative research. In B. L. Wheeler (Ed.), Music therapy research (2nd ed.). Gilsum, N. H.: Barcelona.

Wigram, T. (2004). Improvisation: Methods and techniques for music therapy clinicians, educators and students. London: Jessica Kingsley.

Wigram, T. (1999). Contact in music: The analysis of musical behaviour in children with communication disorder and pervasive developmental disability for differential diagnosis. In De Backer, J., \& Wigram, T. (Eds.). Clinical applications of music therapy in developmental disability, paediatrics, and neurology (pp. 69-92). London: Jessica Kingsley.

Wigram, T., \& Gold, C. (2006). Music therapy in the assessment and treatment of autistic spectrum disorder: Clinical application and research evidence. Child: Care, Health and Development, 32(5), 535-542._https://doi.org/10.1111/j.1365-2214.2006.00615.x 
Wilson, C. (1976). The use of rock music as a reward in behavior therapy with children. Journal of Music Therapy, 13(1), 39-48. https://doi.org/10.1093/jmt/13.1.39

Young, S. (2000). ADHD children grown up: An empirical review. Counselling Psychology Quarterly, 13(2), 191-200. Retrieved from http://search.proquest.com/docview/57727020/

Zhang, F., Liu, K., An, P., You, C., Teng, L., \& Liu, Q. (2017). Music therapy for attention deficit hyperactivity disorder (ADHD) in children and adolescents. Cochrane Database of Systematic Reviews, 5. https://doi.org/10.1002/14651858.CD010032.pub2 